\title{
Kapang Kontaminan Pada Ikan Toreh (Hyporhamphus affinis) yang dijual di Pasar Tradisional Kota Ternate Maluku Utara
}

\author{
NURHASANAH ${ }^{1}$, SUNDARI $^{1}$ \\ ${ }^{1}$ Program Studi Pendidikan Biologi, FKIP Universitas Khairun Ternate \\ Jl. Bandara Baabullah kampus 1 Unkhair Akehuda Kota Ternate, Maluku Utara. 92714 \\ Email: sundariunkhair08@gmail.com
}

Received 15 February 2018; Received in revised form 8 March 2018; Accepted 8 April 2018; Available online 27 June 2018

\begin{abstract}
Dried fish from fish Julung (Hyporhamphus affinis) is one type of fish food products that are found in the traditional market of Ternate city. This product is commonly known as fish toreh. The main problem of this product is storage packaging by using an open bamboo set that can be contaminated by various microbes. The purpose of this study was to inventory and identification of contaminant molds isolated from dried fish of $H$. affinis on a 17-day storage period. The research was conducted in Mathematic and Natural Science laboratory by using dried fish smoke (toreh) from $H$. affinis obtained from traditional market in Ternate city. Isolation and identification of molds using standard microbiological procedures. Media growth of mold using Potato Dextrose Agar (PDA). Several genus and species of mold found as contaminant mold are Aspergillus spp., Eurotium spp., Torula spp., Cladosporium spp., Polypaecilum pisce and Catenaria fuliginea.
\end{abstract}

Keywords: dried fish, fish toreh, Hyporhamphus affinis, mold, traditional market

\section{INTISARI}

Ikan asap kering dari ikan Julung (Hyporhamphus affinis) adalah salah satu jenis produk makanan ikan yang banyak ditemukan di pasar tradisional kota Ternate. Produk ini biasa dikenal sebagai ikan toreh. Masalah utama dari produk ini adalah kemasan penyimpanan dengan menggunakan satu set bambu terbuka yang dapat terkontaminasi oleh berbagai mikroba. Tujuan dari penelitian ini adalah untuk menginventarisasi dan identifikasi kapang kontaminan yang diisolasi dari ikan kering toreh (H. affinis) pada lama penyimpanan sampai dengan 17 hari. Penelitian ini dilakukan di laboratorium MIPA dengan menggunakan ikan asap kering (toreh) dari ikan Julung yang diperoleh dari pasar tradisional di kota Ternate. Isolasi dan identifikasi kapang menggunakan prosedur mikrobiologi standar. Media pertumbuhan kapang dengan menggunakan Potato Dextrose Agar (PDA). Beberapa genus dan spesies kapang yang ditemukan sebagai kapang kontaminan adalah Aspergillus spp., Eurotium spp., Torula spp, Cladosporium spp., Polypaecilum pisce dan Catenaria fuliginea.

Kata Kunci: Hyporhamphus affinis, ikan asap kering, ikan toreh, kapang, pasar tradisional

\section{PENDAHULUAN}

Salah satu produk pengolahan ikan Julung di Maluku Utara khususnya di Tobelo dan pulau Ternate adalah ikan asap kering yang dikenal dengan nama daerah ikan toreh. Produksi ikan toreh dilakukan dalam skala industri rumah tangga dalam rangka diversifikasi produk ikan. Ikan toreh merupakan salah satu jenis pangan khas pulau Ternate. Ikan toreh merupakan salah satu jenis ikan favorit masyarakat Ternate selain ikan cakalang fufu (Nurhayati, 2005). Menurut Terminologi FAO, menyatakan bahwa kategori ikan olahan tradisional adalah ikan asap, ikan kering dan ikan asin yang diolah secara sederhana oleh masyarakat (Hastuti $d k k ., 2011)$. Ikan toreh merupakan kategori ikan olahan tradisional.

Teknik pengolahan ikan toreh dengan pengasapan merupakan upaya pengawetan bahan pangan. Pengasapan ikan adalah penggabungan dari proses pengeringan, dan pemberian asap dengan tujuan mencegah kerusakan ikan (Lekahena and Jamin, 2018), walaupun demikian, pengasapan ikan pada saat ini dilakukan dengan tujuan untuk memberikan warna, tekstur dan flavor yang khas (Budaraga et al., 2016). Kerusakan pada bahan makanan termasuk ikan toreh terjadi sebagai akibat dari proses biodegradasi. Salah satu indikator terjadinya proses biodegradasi adalah keberadaan mikroorganisme (bakteri, kapang, dan kamir) pada bahan makanan 
menyebabkan bahan makanan mengalami penurunan mutu (Aziz, 2014; Herawati, 2008).

Kapang kontaminan merupakan salah satu kelompok mikroorganisme yang dapat menyebabkan penurunan mutu bahan makanan dengan menyebabkan kerusakan/pembusukan (Poulos et al., 2000). Kapang kontaminan dapat tumbuh pada bahan makanan yang aktif air atau kadar air rendah. Pada produk ikan pindang, ikan asin dan ikan asap paling sering ditumbuhi kapang Aspergillus spp. dan Penicillium spp. Kapang kontaminan yang dominan adalah A. flavus dan Polypaecilum sp. (Wheeler et al., 1986; Jay et al., 2005; Handayani $d k k .$, 2017).

Ikan toreh dipasarkan secara tradisional di pasar tradisional kota Ternate yaitu Pasar Higienis Gamalama. Selama proses pemasaran ikan toreh disimpan dalam bambu terbuka (Galafea) dan diikat secara bersusun. Proses penyimpanan yang lama dapat menyebabkan ikan toreh terkontaminasi kapang kontaminan. Keberadaan kapang kontaminan pada makanan, selain menurunkan nilai estetika, juga dapat menghasilkan zat racun (mikotoksin) yang dapat menimbulkan penyakit berbahaya bagi kesehatan manusia (Heruwati, 2002; Maryam, 2008). Penelitian ini bertujuan untuk menginventarisasi jenisjenis mikoflora kontaminan pada ikan toreh yang dijual di pasar tradisional kota Ternate pada berbagai lama penyimpanan.

\section{METODE}

Penelitian ini dilaksanakan dengan metode deskriptif eksploratif dan teknik sampling purposive. Bahan yang digunakan adalah sampel ikan toreh yang dijual pasar terminal kota Ternate serta bahan medium mikrobiologi. Prosedur kerja terdiri dari tahap persiapan sampel ikan toreh yang mempunyai lama simpan 1 minggu ( 8 hari) dan 2 minggu (17 hari) setelah pengiriman dari produsen. Pengenceran suspensi dilakukan hingga pada konsentrasi $10^{-6}$, tahap inokulasi sampel dan isolasi isolat murni kapang, tahap identifikasi dan pengamatan yang terdiri dari pengamatan makroskopis meliputi deskripsi warna koloni, sifat koloni, diameter koloni, ada atau tidaknya warna khas pada dasar media. Pengamatan mikrokopis meliputi deskripsi ciri-ciri yaitu: ada atau tidaknya sekat pada hifa, warna hifa, dinding hifa, diameter hifa, warna konidiofor, panjang konidiofor, konidiofor bercabang atau tidak, dinding konidiofor halus atau tidak, vesikula, metula warna fialida, ukuran fialida, bentuk fialida, warna konidia, diameter konidia, dinding konidia (halus/kasar), makrokonidia dan mikrokonidia, klamidospora. Kegiatan identifikasi dilakukan sampai pada tingkat spesies dengan merujuk pada buku Fungi and Food Spoilage oleh Pitt et al. (1985), buku Introduction to Food-Borne Fungi oleh Samson et al. (1981) dan buku Ilustrated Genera of Imperfect Fungi oleh Barnett (1972).

\section{HASIL}

Hasil isolasi dan identifikasi kapang kontaminan pada ikan toreh yang dijual di pasar tradisional di kota Ternate pada lama penyimpanan 1 minggu tidak diperoleh kapang kontaminan yang tumbuh, sedangkan pada sampel ikan toreh yang disimpan selama 2 minggu (17 hari) diperoleh 6 isolat kapang kontaminan. Dari ke-enam isolat kapang tersebut terdiri dari 6 genus yaitu: Eurotium, Aspergillus, Cladosporium, Torula, Polypaecilum, dan Catenaria. Hasil identifikasi kapang kontaminan pada ikan toreh yang dijual di pasar tradisional kota Ternate terlihat pada tabel 1 berikut:

Tabel 1. Hasil identifikasi kapang kontaminan pada ikan toreh

\begin{tabular}{cccc}
\hline Nomor & Kode Isolat & Genus & Spesies \\
\hline 1 & T1 & Eurotium & Eurotium sp. \\
\hline 2 & T2 & Aspergillus & Aspergillus niger \\
\hline 3 & T3 & Cladosporium & Cladosporium cladosporioides \\
\hline 4 & T4 & Torula & Torula herbarum \\
\hline 5 & T5 & Polypaecilum & Polypeacilum pisce \\
\hline 6 & T6 & Catenaria & Catenaria fuliginea
\end{tabular}




\section{PEMBAHASAN}

Pada ikan toreh yang dijual di pasar tradisional kota Ternate ditemukan 6 spesies kapang kontaminan (Tabel 1). Genus kapang kontaminan yang ditemukan pada ikan toreh merupakan genus kapang kontaminan yang sering ditemukan pada produk makanan olahan ikan.

Sejalan dengan peryataan Wheeler (1989) bahwa jenis kapang yang tumbuh pada ikan asin, ikan fufu, ikan pindang adalah
Aspergillus spp., Penicillium spp., dan jenis yang dominan antara lain: Polypeacilum pisce dan Aspergillus niger. Beberapa jenis kapang yang ditemukan pada ikan asap (fufu) dan berperan memberikan aroma khas ikan fufu adalah A. glaucus, P. glaucus, A. melleus, E. repens dan E. rubrum (Doe, 2002). Sedangkan kapang Aspergillus flavus, Aspergillus fumigatus, Cladosporium sp., dan Eurotium sp., merupakan kelompok kapang kontaminan (Essien et al., 2005).

Tabel 2. Morfologi dan deskripsi kapang kontaminan pada ikan toreh

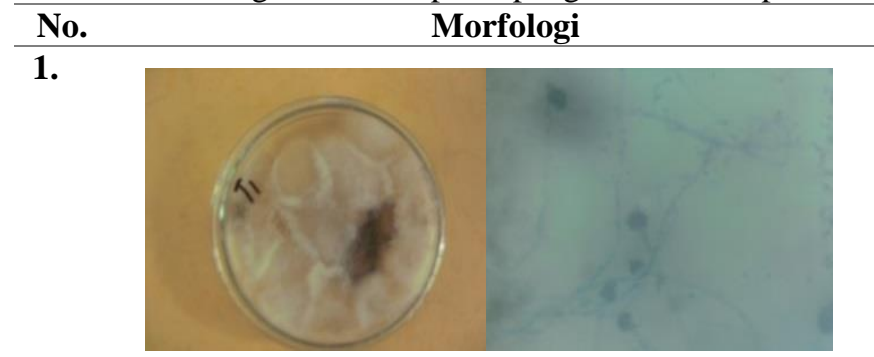

Eurotium sp.

Deskripsi makroskopis koloni berwarna krem dengan dasar koloni berwarna kuning, permukaan koloni berkerut. Deskripsi mikroskopik hifa berwarna hialin dengan banyak askomata berbentuk bulat tebal

2.

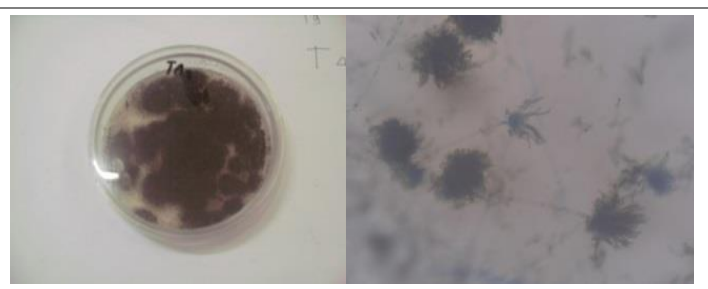

3.

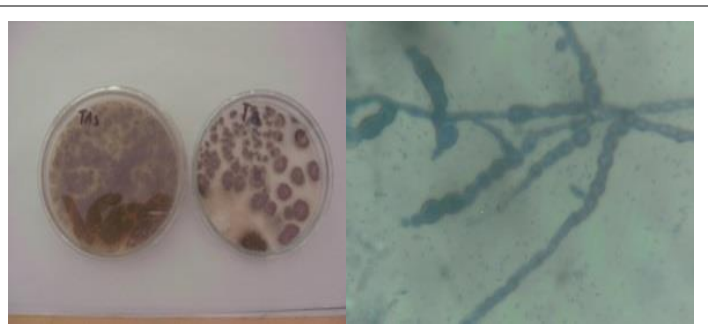

4.

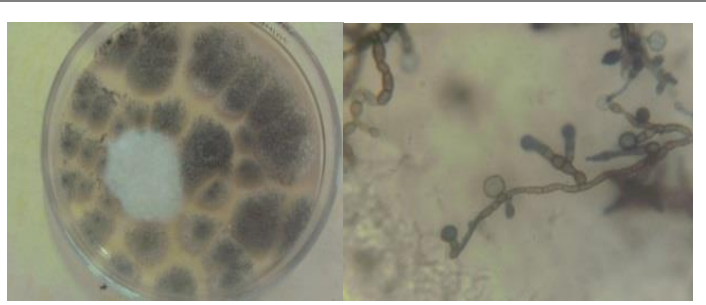

\section{Aspergillus niger}

Deskripsi makroskopis berwarna putih sampai hitam bersporulasi. Dasar koloni hitam. Deskripsi mikroskipis hifa berwarna hialin bersepta, konidia bentuk bulat berwarna coklat kehitaman berornamen, kepala konidia berwarna hitam

\section{Cladosporium cladosoproides}

Deskripsi makroskopis koloni berwarna hijau tua kecoklatandengan dasar koloni berwarna hitam. Deskripsi mikroskopis konidiofor teletak lateral atau terminal di ujung hifa. Konidia membentuk rantai makropetal berwarna coklat kehijauan berdinding kasar

\section{Torula herbarum}

Deskripsi makroskopis koloni berwarna hijau tua kehitaman. Deskripsi mikroskopis konidiofor pendek dan bercabang sederhana, memiliki blastopora bersekat

5.

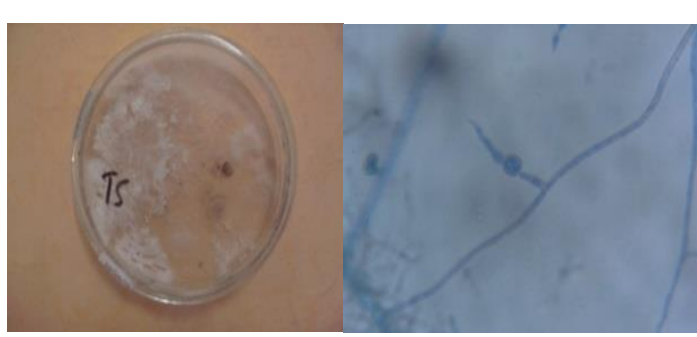

Polypeacilium pisce

Deskripsi makroskopis koloni berwarna putih krem, dasar koloni kekuningan tekstur koloni longgar. Deskripsi mikroskopis konidiofor tidak bersekat dengan clamydospora pada sisi lateral. Konidio berbentuk globose dengan tekstur kasar 


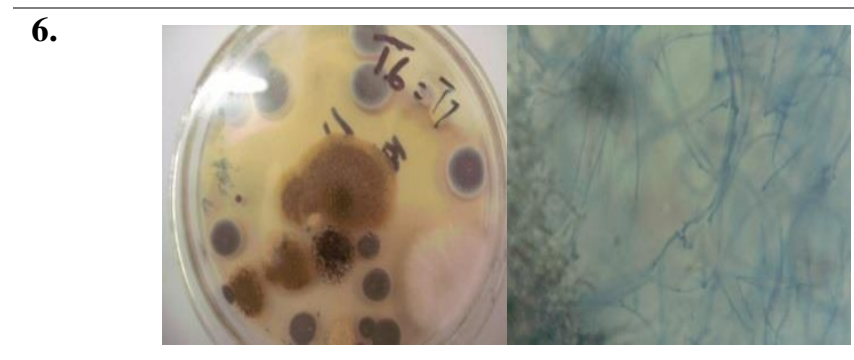

Catenaria fagilinie

Deskripsi makroskopis koloni berwarna hijau tua keabu-abuan, tekstur padat beludru. Dasar koloni berwarna coklat. Deskripsi mikroskopis konidiofor tidak bersekat dengan blastopora ukuran kecil di bagian lateral konidiofor.

Dapat diketahui bahwa pertumbuhan dari 6 genus kapang yang ditemukan dalam penelitian ini dipengaruhi oleh kadar air yang semakin menurun berkisar antara 0,80 - 0,70. Pada saat ikan toreh diasap dan dikeringkan akan menyebabkan tumbuhnya kapang jenis xerofilik yang bersifat toksik.

Di antara genus Aspergillus spp., Eurotium spp., Torula spp., Cladosporium spp, Polypaecilum dan Catenaria sp. yang ditemukan pada ikan toreh, ditemukan Aspergillus niger dan Torula herbarum yang merupakan spesies yang paling dominan, dengan jumlah koloni 1,20 x $103 \mathrm{cfu} /$ gram sampel dan ditemukan pada lama penyimpanan di atas 17 hari.

Hasil penelitian ini merupakan paparan deskripsi hasil inventarisasi dan identifikasi kapang mikoflora kontaminan pada ikan toreh yang dijual di pasar tradisional di kota Ternate. Sampai saat ini, belum ada informasi tentang jenis-jenis mikroba kontaminan yang terdapat pada ikan toreh yang disimpan cukup lama selama proses penjualannya.

\section{KESIMPULAN}

Berdasarkan hasil penelitian ini dapat disimpulkan bahwa pada ikan toreh yang disimpan selama lebih dari 14 hari (2 minggu) yang dijual di pasar tradisional di kota Ternate ditemukan 6 spesies kapang kontaminan yaitu Aspergillus spp., Eurotium spp., Torula spp., Cladosporium spp., Polypaecilum pisce and Catenaria fuliginea.

\section{DAFTAR PUSTAKA}

Aziz IR. 2014. Potency of Pseudomonas aeruginosa as Bioremediation using diazinon. In Proceeding the First International Conference on Science (ICOS-1). p. 104-108. ISBN 978-60272198-0-9.
Budaraga IK. 2016. Effect Combination Treatment Different Concentration of Liquid Smoke, Immersion Duration, Packaging and Storage Duration to Organoleptic quality Fillet Tilapia Fish (Oreochromisniloticus). International Journal of Advanced Scientific and Technical Research. vol 6(2): 228-240.

Doe PE. 2002. Fish drying. Safety and quality issues in fish processing. Florida: CRC Press. p. 350-359.

Essien JP, Akpan EJ, Essien EP. 2005. Studies on mould growth and biomass production using waste banana peel. Bioresource Technology. vol 96(13): 1451-1456.

Handayani BR, Kusumo BD, Werdiningsih W, Rahayu TI, Hariani H. 2017. Kajian Mutu Organoleptik dan Daya Simpan Pindang Tongkol Dengan Perlakuan Jenis Air dan Lama Pengukusan. Pro Food. vol 3(1): 194-199.

Hastuti US, Dipu Y, Mariyanti M. 2011. Isolasi dan Identifikasi Mikoflora Kapang Kontaminan pada Kue Pia yang Dijual di Kota Malang. In Proceeding Biology Education Conference: Biology, Science, Enviromental, and Learning. vol. 8(1): 461-466.

Herawati H. 2008. Penentuan Umur Simpan Pada Produk Pangan. Jurnal Litbang Pertanian. vol 27(4): 124-130.

Heruwati ES. 2002. Pengelolan Ikan Secara Tradisional: Prospek dan Peluang Pengembangan. Jurnal Litbang Pertanian. vol 21(3): 92-99.

Jay JM, Loessner MJ, Golden DA. 2005. Mycotoxins. Modern food microbiology. Boston: Springer. p.709-726.

Lekahena VNJ and Jamin R. 2018. The Quality of Smoked Skipjack during Storage Time at Room Temperature. In IOP Conference Series: Earth and 
Environmental Science. vol. 175(1): 012003. IOP Publishing.

Maryam R. 2002. Mewaspadai Bahaya Kontaminasi Mikotoksin Pada Makanan. [Laporan]. Falsafah Sains, Institut Pertanian Bogor.

Nurhayati. 2005. Sifat Fisika Air Laut di Perairan Maluku Utara. [Laporan Akhir]. Ekspedisi Halmahera, September 2005.
Poulos PG, Critchley J, Diaz Jr RE. 2000. U.S. Patent No. 6,132,786. Washington, DC: U.S. Patent and Trademark Office.

Wheeler K A, Hocking AD, Pitt JI, Anggawati AM.1986. Fungi associated with Indonesia dreid Fish Food Microbiol. vol (3): 351-357. 